\title{
sciendo
}

\section{THE EFFECT OF COMBINED FEED ADDITIVES ON GROWING PIGS' PERFORMANCE AND DIGESTIVE TRACT PARAMETERS}

\author{
Piotr Nowak ${ }^{1}$, Małgorzata Kasprowicz-Potocka ${ }^{1 *}$, Anita Zaworska ${ }^{1}$, Włodzimierz Nowak ${ }^{1}$, Barbara \\ Stefańska ${ }^{1}$, Anna Sip ${ }^{2}$, Włodzimierz Grajek ${ }^{2}$, Katarzyna Grajek ${ }^{3}$, Andrzej Frankiewicz ${ }^{1}$ \\ 'Department of Animal Nutrition, Poznań University of Life Sciences, Wołyńska 33, 60-637 Poznań, \\ Poland \\ ${ }^{2}$ Department of Biotechnology and Food Microbiology, Poznań University of Life Sciences, Wojska \\ Polskiego 48, 60-627 Poznań, Poland \\ ${ }^{3}$ Department of Innovative Biomaterials and Nanotechnologies, Institute of Natural Fibres and Medici- \\ nal Plants, Wojska Polskiego 71b, 60-630 Poznań, Poland \\ •Corresponding author: malgorzata.potocka@up.poznan.pl
}

\begin{abstract}
The aim of the research was to determine the affectivity of $\mathbf{4}$ different eubiotic preparations on the growth performance of pigs, microbial status, the integrity of intestinal mucosa, and some blood parameters. The experiment was conducted for 28 days on 48 male piglets allocated to six dietary treatments. Group 1 was offered a diet without eubiotic; 2 - a diet with acids mixture; 3 - phytobiotic, medium-chain fatty acids (MCFA) and yeast; 4 - probiotic, MCFA, and yeast; 5 phytobiotic, probiotic, acids mixture, and sodium butyrate; 6 - phytobiotic, probiotic, MCFA, and sodium butyrate. The average daily weight gains and feed intake were recorded. Blood samples, digesta samples, and ileal tissue samples were collected for studies. There was no significant difference in gain, feed intake, or FCR among the treatments as well as in the ileal and caecal pH value, microbial content, and total SCFA content in caecal digesta. Ammonia content in ileal digesta was significantly higher in comparison with other groups and in caecal digesta was significantly higher in group 6 in comparison with groups 1 and 2 . Villi height was significantly higher $(P<0.05)$ in groups 2, 3 and 6 compared to the control. Villi height to crypt depth ratio was significantly higher $(P<0.05)$ in groups 5 and 2, but the most promising effects seem to be from combinations 3 and 4. In comparison with control: in groups 2,3 and 5 higher ALT, glucose and triglyceride; in groups 3, 4 and 5 higher total protein and cholesterol; in group 4 higher albumin and in group 6 higher BUN, were found. Generally, used eubiotic preparations affected gut morphology and some blood parameters but did not affect microbiota, pig growth or feed utilization.
\end{abstract}

Key words: eubiotic, pig, performance, microflora

Currently, the basic problem in the rearing of piglets is the correct and rapid development of the gastrointestinal tract. By the development of the gastrointestinal 
tract should be understood the proper condition of microflora and villi in the intestine as well as the appropriate $\mathrm{pH}$ in its individual parts and also preventing diarrhoea incidents. An effective strategy for the development of the digestive tract should focus on all these factors and could be realized by using different feed additives.

Natural feed additives as probiotics, phytobiotics, or organic and inorganic acids are commonly used in animal nutrition in Europe and are considered as safe. These products, also called "Eubiotics" (Greek "Eubiosis"), affect microbiota balance in the gastrointestinal tract. The gut microbial ecosystem is fundamental in proper activity of immunological system and also for maintaining homeostasis of the pigs (Brestoff and Artis, 2013). According to current knowledge of the host-microbial relationship, strategies including the use of eubiotics may promote animal health and growth. Supplementation of piglet diets with probiotics (and also prebiotics or synbiotics) can increase microbial diversity, which can help to exclude pathogenic microbes (Hill et al., 2014). Probiotics, when used in the appropriate amounts, can prevent microbial imbalance by altering intestinal populations, epithelial lining, and the gut-associated lymphoid tissues (Metzler et al., 2005; Santini et al., 2010; Liao and Nyachoti, 2017). Moreover, the use of a mixture of several strains of microorganisms increases its efficacy, especially if the bacteria differ in the fermentation profile and prevent the development of different pathogens (Barszcz et al., 2016; Piyadeatsoontorn et al., 2018). Yeast generally positively affects feed intake and young pig's performance, as well as microflora and ileum structure (Pereira et al., 2012; Bael and Roxas, 2013). The phytobiotics, containing the bioactive substances, are commonly used in pharmacology as fragrances and preservatives for foods (Grashorn, 2010; Gheisar and Kim, 2018), but they may also present antibacterial, antiviral and antifungal properties (Vidanarachchi et al., 2005). Organic and inorganic acids (fumaric, benzoic, lactic, phosphoric etc.) or their salts could effectively improve environment of digestive tract by reducing $\mathrm{pH}$, which favours development of health promoting microorganisms and nutrients utilization (Suiryanrayna and Ramana, 2015). Organic acids salts, e.g. sodium butyrate can play an important role in maintaining the integrity of intestinal mucosa (Fang et al., 2014), and also in improving performance and decreasing diarrhoea incidence in weaned piglets by modulation of intestinal permeability and the bacterial communities in the ileum and colon (Huang et al., 2015). Medium chain fatty acids are a source of easily absorbed energy and affect the growth of intestinal villi, improve digestion and absorption of nutrients and the growth of piglets (Hong et al., 2012; Chwen et al., 2013; Hanczakowska et al., 2013; $\mathrm{Li}$ et al., 2015). The improvement in intestinal environment is beneficial for the nutrient absorption, which could be improved by higher levels of serum triglyceride and glucose and lower levels of nitrogen and BUN (blood urea nitrogen). Rosell and Zimmerman (1985) reported that the declined plasma urea concentration was relevant to the improved efficiency of nitrogen utilization (Fang et al., 2014). Moreover, some of the feed additives can positively affect animal performance (Costa et al., 2011; Liu et al., 2018) and quality of welfare by reducing e.g. ammonia emissions from pig breeding (Vidanarachchi et al., 2005; Bartoš et al., 2016; Liu et al., 2018).

According to literature, using more than one feed additive could be more efficient than using one; however, it is highly dependent on the type, composition and form of 
the administered preparation (Botsoglou et al., 2002; Windisch et al., 2008; Liu et al., 2018). This study attempts to verify the recipes of eubiotic preparations developed in earlier studies (Nowak et al., 2017) and enriched with functional ingredients. We expected that used active promoters of metabolic function and microflora will positively affect growth and health status of pigs.

The aim of the research was to recognize the effect of eubiotic preparations containing probiotic bacteria strains, yeast, phytobiotics or acids and/or their salts in different combinations on the growth performance of pigs, microbial status, intestinal mucosa and some blood parameters.

\section{Material and methods}

\section{Ethic statement}

All the experimental procedures complied with the guidelines of the Local Ethical Committee for Experiments on Animals in Poznań regarding animal experimentation and the animal care under study (EU Directive 2010/63/EU for animal experiments). The pigs received all the necessary veterinary vaccinations and had unlimited access to water and feed.

\section{Animals, diets and experimental design}

The growth experiment was conducted on 48 castrated male pigs $(\mathrm{P} 76 \times$ Naima) of about $10 \mathrm{~kg}$ body weight (BW). The pigs were allocated to six dietary treatments according to their BW (8 replications each) and kept in individual pens on straw bedding. All diets were offered in mash form according to the experimental design (Table 1). The basal diet was prepared according to pig requirements (GfE, 2006) (Table 2).

Table 1. Experimental design

\begin{tabular}{ll}
\hline \multicolumn{1}{c}{ Name of group } & \multicolumn{1}{c}{ Eubiotic composition } \\
\hline Group 1 & Wheat bran $2 \%$ \\
Group 2 & Acids mixture $0.2 \%$, wheat bran $1.8 \%$ \\
Group 3 & Phytobiotics $0.2 \%$, MCFA $0.3 \%$, yeast $1 \%$, wheat bran $0.5 \%$ \\
Group 4 & Probiotic $0.12 \%$, MCFA $0.3 \%$, yeast $1 \%$, wheat bran $0.58 \%$ \\
Group 5 & $\begin{array}{l}\text { Phytobiotics } 0.2 \% \text {, probiotic } 0.12 \% \text {, acids mixture } 0.2 \% \text {, sodium butyrate } 0.3 \%, \\
\text { wheat bran } 1.15 \% \\
\text { Group } 6\end{array}$ \\
& Phytobiotics $0.2 \%$, probiotic $0.12 \%$, MCFA $0.3 \%$, sodium butyrate $0.3 \%$, wheat \\
\hline
\end{tabular}

MCA - medium-chain fatty acids.

A multispecies probiotic bacteria preparation (Leuconostoc mesenteroides, two strains of Enterococcus faecium and Carnobacterium divergens at a ratio of 1:1:1:1) with maltodextrin as a protector was dosed in the total amount of $10^{11} \mathrm{CFU} / \mathrm{t}$ of feed. The preparation formula was prepared at Poznań University of Life Sciences and the 
individual strains were deposited in the Polish Patent Collection of Microorganisms in Wrocław under the Accession Numbers: L. mesenteroides PKM B/00096; E. faecium PKM B/00097; C.divergens PKM B/00099 and E. faecium PKM B/00098. The formulation and dosage of the probiotic preparations were determined based on the results of in vitro studies. Probiotic was encapsulated with fatty acids.

Table 2. The composition and nutritional value of the basal diet

\begin{tabular}{|c|c|}
\hline Components & $(\%)$ \\
\hline soybean meal & 25.35 \\
\hline corn & 30.00 \\
\hline wheat & 19.10 \\
\hline barley & 20.00 \\
\hline soybean oil & 0.30 \\
\hline limestone & 1.10 \\
\hline monocalcium phosphate & 0.90 \\
\hline L-Lysine $(76 \%)$ & 0.40 \\
\hline methionine $(99 \%)$ & 0.20 \\
\hline salt & 0.35 \\
\hline premix* & 0.30 \\
\hline eubiotic & 2.00 \\
\hline Calculated nutritional value & $(\%)$ \\
\hline $\mathrm{ME}(\mathrm{MJ} / \mathrm{kg})$ & 13.0 \\
\hline crude protein & 191.7 \\
\hline crude fibre & 34.6 \\
\hline lysine & 11.8 \\
\hline methionine + cystine & 7.7 \\
\hline $\mathrm{Ca}$ & 7.4 \\
\hline $\mathrm{P}$ & 6.3 \\
\hline $\mathrm{Na}$ & 1.6 \\
\hline
\end{tabular}

*Mineral and vitamin premix contained, per kg: choline chloride 40,000 mg, Fe 15,000 mg, Cu 4,000 mg, Co $60 \mathrm{mg}$, Mn 6,000 mg, Zn 15,000 mg, I $120 \mathrm{mg}$, Se $30 \mathrm{mg}$, antioxidants (butylated hydroxyanisole, butylated hydroxytoluene); 1,500,000 IU vitamin A, 300,000 IU vitamin $\mathrm{D}_{3}, 10,500 \mathrm{mg}$ vitamin $\mathrm{E}, 220 \mathrm{mg}$ vitamin $\mathrm{K}_{3}, 220$ $\mathrm{mg}$ vitamin $\mathrm{B}_{1}, 600 \mathrm{mg}$ vitamin $\mathrm{B}_{2}, 450 \mathrm{mg}$ vitamin $\mathrm{B}_{6}, 1,500 \mathrm{mg}$ pantothenic acid, 3,000 mg nicotinic acid, 300 $\mathrm{mg}$ folic acid, $3,700 \mathrm{mcg}$ vitamin $\mathrm{B}_{12}, 15,000 \mathrm{mcg}$ biotin, $260 \mathrm{~g} \mathrm{Ca}$.

As a phytobiotic, Oregano vulgaris and Thymus vulgaris water extracts were used in the total amount of $200 \mathrm{~g} / \mathrm{t}$ of feed (1:1). Water extracts of thyme and oregano used in this experiment were prepared at the Institute of Agricultural and Food Biotechnology, Department of Food Concentrates and Starch Products (Poznań, Poland). For the extraction of biologically active substances, the method of solid-liquid separation was used. The dry herbal material was pre-treated by circulation pump maceration. The obtained extracts were filtrated on plate filters and then concentrated on a vacuum evaporator and spray-dried. The dry extracts were standardised 
and the assays were carried out according to pharmacopoeial methods. The extracts contained, respectively, $0.33 \%$ and $0.28 \%$ of flavonoids recalculated as hyperoside; $17.80 \%$ and $21.50 \%$ of polyphenols recalculated as rosemary acid, and $5.07 \%$ and $5.80 \%$ of tannins recalculated as pyrogallol. The phytobiotics concentration was based on the earlier experiment (Nowak et al., 2017).

Yeast Yarrowia lipolytica (Skotan, Chorzów, Poland), medium chain fatty acids caprylic-caprinic acid (MCFA) (Noack, Poland), organic and inorganic acid mixture containing phosphoric, citric, fumaric, tartaric and malic acids (BARACID, JHJ, Poland) and sodium butyrate (INTEST - PLUS S 95\%, Galwet, Poland) were used as the components of the particular eubiotic mixtures. Wheat bran was used as a carrier.

The experiment lasted 28 days. The average daily weight gains (ADG) and feed intake (FI) were recorded and at the end the average feed conversion ratio (FCR) was calculated. Blood samples were collected from the auricular vein on the last day of experiment. Serum samples were prepared by centrifugation at 1,500 g for $15 \mathrm{~min}$ at $4{ }^{\circ} \mathrm{C}$, and they were stored at $-40^{\circ} \mathrm{C}$ for further analyses. Directly after euthanasia (ca. $10 \mathrm{~min}$ ), ileal tissue samples were collected for morphometric studies. In the ileal and caecal digesta, $\mathrm{pH}$ values were measured and also microbial analyses were performed. Digesta were sampled and frozen $\left(-20^{\circ} \mathrm{C}\right)$ to determine dry matter and ammonia.

\section{Chemical analysis}

The $\mathrm{pH}$ of the digesta was measured using a microelectrode and a $\mathrm{pH}$ meter (model 301, Hanna Instruments, Vila do Conde, Portugal). Ammonia was extracted and analysed by the spectrometric method using a Nessler reagent (POCh, Gliwice, Poland). The SCFA analysis was performed according to the procedure described by Barszcz et al. (2011) on HP 5890 Series II gas chromatograph (Hewlett Packard, Waldbronn, Germany) with a flame-ionization detector and Supelco Nukol-fused silica capillary column (Supelco, Bellafonte, USA; $30 \mathrm{~m} \times 0.25 \mathrm{~mm}$ i.d.; $0.25 \mathrm{~mm}$ ). Helium was used as the carrier gas.

Samples of fresh digesta for microbial analysis were prepared by adding $27 \mathrm{ml}$ of buffered peptone water (Oxoid, Hampshire, UK) to $3 \mathrm{~g}$ of samples and homogenized for $30 \mathrm{~s}$ in a laboratory stomacher. Microbial counts were determined using a decimal dilution series of homogenised samples. The total bacteria count was determined by the standard plate method using a Columbia LAB-AGAR + 5\% KB Agar (Biocorp, Warsaw, Poland) after a $24 \mathrm{~h}$ incubation at $37^{\circ} \mathrm{C}$, and a lactic acid bacteria count using MRS LAB-AGAR (Biocorp, Warsaw, Poland) after a 72 -h incubation at $30^{\circ} \mathrm{C}$. The yeast content was calculated using YGC Agar (Oxoid, Hampshire, UK) after incubation at $25^{\circ} \mathrm{C}$ for 3-5 d. Coliform bacteria were determined using McConkey agar (Biocorp, Warsaw, Poland) after a $24 \mathrm{~h}$ incubation at $37^{\circ} \mathrm{C}$.

Enzyme activity (ALT, AST), total protein, BUN, triglycerides, glucose and total cholesterol concentrations in the blood serum were determined using Alpha Diagnostics (Warsaw, Poland) and Pointe Scientific (Warsaw, Poland) commercial kits. Analyses were performed using Microplate reader synergy 2 (BioTek Instruments, Winooski, USA). 
For morphometric analysis the ileum tissue samples were fixed in $4 \%$ formalin, and after that washed and dehydrated in ethyl alcohol of increasing concentration, xylene, and then embedded in paraffin. Sections with a thickness of $10 \mu \mathrm{m}$ were cut on a microtome Thermo Shandon. They were then stained with periodic acid-Schiff (PAS) method. Preparations were analysed by Optek UB-200 microscope equipped with the ToupCam ${ }^{\mathrm{TM}}$ digital camera and the Multiscan 18.03 computer image analysis program (Computer Scanning Systems II, Warsaw). Villi height, villi area and crypt depth were measured. For the measurement of the intestinal villi height, they were randomly selected from the cross section of the 10 villi. Height was measured from the top of the villus to its base at the mouth of the intestinal crypt. Then the surface of the villi was calculated according to the formula of Uni et al. (1998).

\section{Statistical analysis}

The significance of differences between control and experimental groups was calculated using one-way ANOVA with Duncan's post-hoc test, and an alpha level of $\mathrm{P}<0.05$ was used to assess the significance among means. The statistical analysis was performed using SAS, ver. 5.0. (Iowa, USA).

\section{Results}

No health problems were encountered in pigs during the trial. There were no significant differences in gains, feed intake or FCR among treatments $(\mathrm{P}>0.05)$ (Table 3). The daily gains ranged between 0.670 and $0.752 \mathrm{~kg}$, feed consumption ranged from 31.6 to $34.3 \mathrm{~kg}$ and FCR from 1.6 to $1.75 \mathrm{~kg} / \mathrm{kg}$.

Table 3. Body mass, body gain, feed intake, and feed utilization of the pigs in the experiment

\begin{tabular}{|c|c|c|c|c|c|c|c|c|}
\hline & \multicolumn{6}{|c|}{ Groups } & \multirow{2}{*}{ SEM } & \multirow{2}{*}{ P-value } \\
\hline & 1 & 2 & 3 & 4 & 5 & 6 & & \\
\hline Initial BW (kg) & 10.39 & 10.46 & 10.49 & 10.38 & 10.46 & 10.46 & 0.12 & 0.999 \\
\hline Final BW (kg) & 29.16 & 31.53 & 30.04 & 30.89 & 29.46 & 29.94 & 0.37 & 0.455 \\
\hline Daily gains $(\mathrm{kg})$ & 0.670 & 0.752 & 0.698 & 0.733 & 0.678 & 0.696 & 0.32 & 0.280 \\
\hline Feed intake $(\mathrm{kg})$ & 31.65 & 33.66 & 32.85 & 34.31 & 31.46 & 33.36 & 0.54 & 0.232 \\
\hline FCR $(\mathrm{kg} / \mathrm{kg})$ & 1.69 & 1.60 & 1.69 & 1.66 & 1.75 & 1.72 & 0.02 & 0.120 \\
\hline
\end{tabular}

SEM - standard error of mean, BW - body weight, FCR - feed conversion ratio.

There was no significant difference in ileal and caecal $\mathrm{pH}$ value, but significant differences were found in ileal and caecal ammonia concentration (Table 4). Ileal ammonia content was significantly higher in group 6 as compared to other groups. In group 6, ammonia content in caecal digesta was also significantly higher in comparison with groups 1 and 2. No differences were found in microbial counts and total and particular SCFA content in caecal digesta. 
Table 4. Ileal and caecal $\mathrm{pH}$, ammonia content and microbial counts in fresh digesta of pigs

\begin{tabular}{|c|c|c|c|c|c|c|c|c|}
\hline & \multicolumn{6}{|c|}{ Groups } & \multirow{2}{*}{ SEM } & \multirow{2}{*}{ P-value } \\
\hline & 1 & 2 & 3 & 4 & 5 & 6 & & \\
\hline Ileal $\mathrm{pH}$ & 6.48 & 6.50 & 6.55 & 6.52 & 6.33 & 6.44 & 0.05 & 0.861 \\
\hline Caecal pH & 5.40 & 5.52 & 5.40 & 5.18 & 5.46 & 5.28 & 0.05 & 0.504 \\
\hline Ileal ammonia (mM/g) & $8.13 \mathrm{~b}$ & $8.13 \mathrm{~b}$ & $7.58 \mathrm{~b}$ & $6.75 \mathrm{~b}$ & $9.32 \mathrm{~b}$ & $12.38 \mathrm{a}$ & 0.59 & 0.031 \\
\hline Caecal ammonia (mM/g) & $9.16 \mathrm{bc}$ & $8.14 \mathrm{c}$ & $10.71 \mathrm{abc}$ & $12.25 \mathrm{ab}$ & $12.08 \mathrm{ab}$ & $13.50 \mathrm{a}$ & 0.51 & 0.030 \\
\hline Total caecal SCFA (mM/g) & 71.1 & 76.22 & 68.39 & 63.27 & 70.72 & 66.29 & 1.74 & 0.379 \\
\hline \multicolumn{9}{|c|}{ Microbial groups content (log CFU/g) } \\
\hline Yeast and moulds & 4.75 & 5.11 & 4.40 & 4.38 & 4.43 & 4.64 & 0.46 & 0.669 \\
\hline Lactic acid bacteria & 8.81 & 8.91 & 7.74 & 8.44 & 8.83 & 8.04 & 0.11 & 0.250 \\
\hline Enterobacteriaceae & 6.68 & 6.41 & 7.34 & 6.28 & 7.08 & 6.32 & 0.39 & 0.642 \\
\hline Total bacteria counts & 8.98 & 9.47 & 8.56 & 9.40 & 9.28 & 8.46 & 0.43 & 0.319 \\
\hline
\end{tabular}

a, b, c - means with different letters within a row are significantly different $(\mathrm{P}<0.05)$.

SEM - standard error of mean.

Table 5. Morphometric parameters of ileum

\begin{tabular}{|c|c|c|c|c|c|c|c|c|}
\hline & \multicolumn{6}{|c|}{ Groups } & \multirow{2}{*}{ SEM } & \multirow{2}{*}{$\mathrm{P}$-value } \\
\hline & 1 & 2 & 3 & 4 & 5 & 6 & & \\
\hline $\begin{array}{l}\text { Villi } \\
\text { height } \\
(\mu \mathrm{m})\end{array}$ & $422 \mathrm{c}$ & $487 \mathrm{a}$ & $462 \mathrm{ab}$ & $437 \mathrm{bc}$ & $428 \mathrm{bc}$ & $481 \mathrm{a}$ & 2.65 & $<0.001$ \\
\hline $\begin{array}{l}\text { Villi area } \\
(\mu \mathrm{m})\end{array}$ & $236353 \mathrm{ab}$ & $250424 \mathrm{a}$ & $214724 \mathrm{~b}$ & $215771 \mathrm{~b}$ & $253410 \mathrm{a}$ & $254812 \mathrm{a}$ & 1154 & 0.022 \\
\hline $\begin{array}{l}\text { Crypt } \\
\text { depth } \\
(\mu \mathrm{m})\end{array}$ & $358 \mathrm{a}$ & $354 \mathrm{a}$ & $368 \mathrm{a}$ & $326 \mathrm{~b}$ & $280 \mathrm{c}$ & $357 \mathrm{a}$ & 1.95 & $<0.001$ \\
\hline $\begin{array}{l}\text { Villi } \\
\text { height } \\
\text { to crypt } \\
\text { depth } \\
\text { ratio }\end{array}$ & $1.23 \mathrm{c}$ & $1.46 \mathrm{ab}$ & $1.29 \mathrm{c}$ & $1.35 \mathrm{bc}$ & $1.53 \mathrm{a}$ & $1.38 \mathrm{bc}$ & 0.22 & $<0.001$ \\
\hline
\end{tabular}

$\mathrm{a}, \mathrm{b}, \mathrm{c}-$ means with different letters within a row are significantly different $(\mathrm{P}<0.05)$.

SEM - standard error of mean.

Significant differences were observed in morphometric parameters of ileum (Table 5). Villi height were significantly higher $(\mathrm{P}<0.05)$ in groups 2,3 and 6 as compared to the control and in groups 3 and 4 villi height was significantly lower $(\mathrm{P}<0.05)$ than in the control. There were no differences $(\mathrm{P}>0.05)$ in villi area among experimental groups and control, but in groups 2, 5 and 6 the villi area was significantly greater than in groups 3 and 4 , but crypts depth was significantly lower in groups 4 and 5 than in other groups. Villi height to crypt depth ratio was significantly lower $(\mathrm{P}<0.05)$ in groups 1 and 3 than in groups 5 and 2 . 
Table 6. Blood parameters

\begin{tabular}{|c|c|c|c|c|c|c|c|c|}
\hline \multirow{2}{*}{ Parameters } & \multicolumn{6}{|c|}{ Groups } & \multirow{2}{*}{ SEM } & \multirow{2}{*}{ P-value } \\
\hline & 1 & 2 & 3 & 4 & 5 & 6 & & \\
\hline ALT (IU/L) & $10.1 \mathrm{c}$ & $16.9 \mathrm{a}$ & $16.8 \mathrm{a}$ & $12.0 \mathrm{abc}$ & $16.3 \mathrm{ab}$ & $11.5 \mathrm{bc}$ & 0.8 & 0.011 \\
\hline AST (IU/L) & 8.4 & 11.9 & 9.9 & 9.3 & 8.9 & 7.6 & 0.6 & 0.382 \\
\hline Albumin $(\mathrm{g} / \mathrm{L})$ & $52.1 \mathrm{~b}$ & $56.8 \mathrm{ab}$ & $60.7 \mathrm{ab}$ & $62.9 \mathrm{a}$ & $58.6 \mathrm{ab}$ & $59.6 \mathrm{ab}$ & 1.2 & 0.184 \\
\hline Total protein $(\mathrm{g} / \mathrm{L})$ & $80.3 \mathrm{c}$ & $91.6 \mathrm{bc}$ & $118.4 \mathrm{a}$ & $102.1 \mathrm{ab}$ & $107.5 \mathrm{ab}$ & $92.7 \mathrm{bc}$ & 3.1 & 0.002 \\
\hline Triglycerides $(\mathrm{mg} / \mathrm{L})$ & $529.8 \mathrm{~b}$ & $697.6 \mathrm{a}$ & 775.7 a & $732.5 \mathrm{a}$ & $762.0 \mathrm{a}$ & $632.2 \mathrm{ab}$ & 24.2 & 0.021 \\
\hline Total cholesterol $(\mathrm{g} / \mathrm{L})$ & $875.2 \mathrm{c}$ & $993.1 \mathrm{bc}$ & $1348.0 \mathrm{a}$ & $1218.8 \mathrm{ab}$ & $1211.3 \mathrm{ab}$ & $915.4 \mathrm{c}$ & 44.8 & 0.002 \\
\hline Glucose (mg/L) & $623.3 \mathrm{c}$ & 886.8 b & $1096.4 \mathrm{a}$ & $721.7 \mathrm{c}$ & $668.3 \mathrm{c}$ & $902.4 \mathrm{~b}$ & 38.9 & 0.001 \\
\hline BUN (mg/L) & $149.3 \mathrm{~b}$ & $187.4 \mathrm{ab}$ & $217.4 \mathrm{ab}$ & $216.7 \mathrm{ab}$ & $175.9 \mathrm{~b}$ & $247.7 \mathrm{a}$ & 10.1 & 0.050 \\
\hline
\end{tabular}

a, b, c - means with different letters within a row are significantly different $(\mathrm{P}<0.05)$.

SEM - standard error of mean.

There were found many significant $(\mathrm{P}<0.05)$ differences among groups for all the measured blood serum parameters, except of AST (Table 6). ALT level was generally higher in all the experimental groups in comparison with group 1, but the difference was significant among groups 2, 3 and 5 in comparison with groups 1 and 6 . Albumin concentration in blood serum was higher $(\mathrm{P}<0.05)$ in group 4 than in group 1. Total protein content was lower in group 1 in comparison with groups 3,4 and 5 $(\mathrm{P}<0.05)$ and also in group 3 protein level was significantly higher than in groups 2 and 6. Triglycerides concentration in blood serum was significantly lower in group 1 than in groups 2, 3, 4 and 5. Total cholesterol concentration in serum was higher in groups 3, 4 and 5 than in group 1 or 6 . Glucose concentration was significantly higher in groups 2, 3 and 6 in comparison with groups 1, 4 and 5, and in group 3 was the highest $(\mathrm{P}<0.05)$. In group 6 BUN concentration in blood serum was significantly higher than in group 1 or 5.

\section{Discussion}

Using the mixture of several active substances as feed additive could be more efficient than using them separately, but according to previous data, it is highly dependent on the type, composition, dosage and form of the administered preparation (Botsoglou et al., 2002; Namkung et al., 2004; Windisch et al., 2008; Nowak et al., 2017). The current research is continuation of earlier work by Nowak et al. (2017). Multi-eubiotic composition used in the previous research stimulated digestive tract microflora, but the other observed changes were not beneficial in comparison with separately administered additives (Nowak et al., 2017). Thus in the current research different eubiotic combinations were used. The strategy of proposed mixtures of eubiotics was their complementary action in the gastrointestinal tract, including: (1) development of microflora (probiotic, yeast, phytobiotics); (2) development of intes- 
tine villi (MCFA or sodium butyrate), (3) pH regulation (acids mixture, MCFA) and (4) diarrhoea incidents reduction (phytobiotics, probiotic, acids mixture). In group 2 an effective, commercial acidifier was used as a kind of comparative group. Phytobiotic and probiotic additives were used in these same concentrations as in the research of Nowak et al. (2017). They both were found as effective feed additives which improved pig performance, and positively affected microbiota and fermentation parameters of pigs. Feeding Lactobacillus derived from the pig intestine as probiotics reduced the abundance of Enterobacteriaceae including pathogenic E. coli, reduced incidence of diarrhoea, enhanced immune response during infection and increased weight gain (Fouhse et al., 2016). Phytobiotics containing thyme and oregano did not improve feed intake, but the pig performance results were satisfactory because daily gains in pigs offered phytobiotics were higher, which was a result of better feed utilisation (Nowak et al., 2017). These herbs are also recognised as digestion stimulants and they enhance the synthesis of bile acids in the liver which has a beneficial effect on the digestion and absorption of lipids (Han et al., 2016). Moreover, plant spices stimulate the functioning of pancreatic enzymes and increase the activity of the digestive enzymes of gastric mucosa (Costa et al., 2011).

In the current research used feed additives also did not improve pigs' performance. Numerous factors, such as the environment, management practices, nutrition, additive type and dosage, and animal characteristics (age, species, stage of production) can affect the response to feed additives. Therefore, the non significant effects of additives in the current study could be attributed to the above-mentioned factors. This is especially evident in group 2, where commercial acidifier, well known for its affectivity, was administered in the dosage suggested by the producer. The farm conditions must be considered as an important factor. Generally, it has been suggested that beneficial effects of most additives are clearer in suboptimal and stressful conditions, such as a disease condition, a high stocking density, and bad management practices. The scientific study demands to keep animals according to welfare that generates good environmental and zootechnical conditions and, on the other hand, it makes difficult to demonstrate the effectiveness of some experimental factors. Under favourable rearing conditions without any disease or stress, dietary supplementation with a probiotic had no beneficial effects on growth performance (Houshmand et al., 2011).

The main rule of eubiotics is affecting microbiota balance in the gastrointestinal tract. None of the additives changed the composition of the microflora, which was also confirmed by similar total SCFA content in caecal digesta. In groups 4, 5 and 6 where probiotic bacteria were administered no higher content of lactic acid bacteria or lower content of Enterobacteriaceae was observed (Fouhse et al., 2016). Moreover, in groups 5 and 6, where both probiotic and phytobiotics were present in the eubiotic mixture, the results were worse than in groups 3 and 4 where these additives were used separately. This is in the agreement with previous study of Nowak et al. (2017). It is possible that phytobiotic and probiotic used in these both studies, irrespective of the form of administration (coated or not coated), affected negatively their mutual activity. It could be also confirmed by similar as in the other groups content of lactic acid bacteria, whereas in groups 4, 5 and 6 higher number of these 
bacteria was expected. This could be caused by the antagonistic action of phytobiotic for probiotic bacteria, although in the in vitro study, they showed poor activity against isolated probiotic strains (Grajek et al., 2016). They are also possible other antagonistic activities of other components.

In the current study the presence of acids mixture in feed (groups 2 and 5) did not lower $\mathrm{pH}$ of digesta, which could establish more favorable conditions for bacterial growth (Suiryanrayna and Ramana, 2015). One of the most important reasons is the buffering capacity of the dietary feedstuffs, the presence of other antimicrobial compounds, acid type and concentration, composition of the diet, and experimental environment (Houshmand et al., 2011). Ammonia and SCFA content in digesta are indicators of microbial activity. Ammonia is produced by intestinal bacteria in the digestion of proteins in the intestine. It is transported from the gut to the liver, where it is processed into urea and glutamine (the so-called urea cycle), and then it is removed from the body by the kidneys, and further along with the urine (Meulen and Jansman, 1997). When ammonia is not properly metabolized and removed from the body, it accumulates in the blood. SCFA content did not differ among groups but ammonia content in digesta was significantly higher in group 6. In this group also BUN was higher in comparison with control, which could be the reason of higher ammonia absorption.

Some eubiotics could also affect histological parameters of piglet ileum. Villi height to crypt depth ratio indicates development of intestinal epithelium and is related to absorptive area (Metges, 2010). In the current research this parameter was higher in groups 2 and 5 and villi area also in group 6. In groups 5 and 6 sodium butyrate was added. This substance has been found to improve the growth performance of weaned piglets; inhibit the growth of harmful intestinal bacteria; and promote the nutrient digestion, absorption and gut barrier function of piglets and morphometric parameters of ileum (Fang et al., 2014). Butyric acid is the main energy source for the epithelial cells of the large intestine and is considered to be effective for promoting epithelial growth. Also other acids mixtures can improve intestinal parameters of growing pigs, which is in agreement with current research (Long et al., 2018). Increased epithelial cell proliferation has been observed when short chain fatty acids are given orally or by intravenous injection or gastro-intestinal infusion.

Many eubiotic additives have a positive effect on health, metabolism and absorption of nutrients in animals, which is reflected in the blood biochemistry. The improvement in intestinal environment could be observed as higher levels of serum triglyceride and glucose and lower levels of nitrogen in serum. In the current results in the blood serum of animals from groups 3 and 4 (and also 5) higher level of total protein, triglyceride but also of cholesterol was found in comparison with control. Protein concentration in the blood serum depends from many factors, including the amount of food rich in protein and its synthesis in specialized tissues (primarily in the liver) and the degree of loss of this substance through the digestive system, urinary system, lungs and skin (Muñoz et al., 2012). The higher cholesterol level is generally connected with the supply and management of lipids in the body and especially with liver activity (Rauw et al., 2007). In group 6, BUN and glucose level was higher in comparison with control, which could be the reason of higher ammonia 
absorption. Circulating serum concentrations of glucose, lipoproteins, cholesterol, and triglycerides are the result of the uptake and production by lipogenic tissues and therefore any diet (and also feed intake, feed efficiency and feed intake behaviour of pigs) or genetic-related changes in their levels (Rauw et al., 2007; Muñoz et al., 2012). Some of the values of biochemical blood parameters in experimental groups (albumin, total protein, cholesterol, BUN) but also in control (total cholesterol, total protein) were higher than the values recommended for pigs (Winnicka, 2011). It also should be mentioned that the method of sample collection or storage before analyses can affect values of some parameters.

\section{Conclusions}

In the present research used combinations of eubiotics did not affect gut microflora and did not improve growth of animals and feed utilization. In contrast, they positively affected gut morphology and some blood parameters. From the experimental groups the most promising seems to be a combination where phytobiotic or probiotic, respectively, with MCFA and yeast were used in the mixture.

\section{Acknowledgments}

The study has been carried out within the Project: "Development of eubiotic preparation for farm animals", financed by the National Research and Development Centre for Applied Research Program, PBS1/A8/10/2012.

\section{References}

B a e 1 B.A., R o x a s D.B. (2013). Effects of yeast-based non-nutritional enhancers on the performance of weanling pigs. Philippines J. Vet. Anim. Sci., 39: 71-80.

B ars zc z M., Ta ci a k M., S k o miał J. (2011). A dose-response effects of tannic acid and protein on growth performance, caecal fermentation, colon morphology, and $\beta$-glucuronidase activity of rats. J. Anim. Feed Sci., 20: 613-625.

B arszcz M., Taciak M., Skomiał J. (2016). The effects of inulin, dried Jerusalem artichoke tuber and a multispecies probiotic preparation on microbiota ecology and immune status of the large intestine in young pigs. Arch. Anim. Nutr., 70: 278-292.

B art o š P., D o l a n A, S m u tný L., Š́ íst ková M., C e lj a k I., Š o c h M., H a vel k a Z. (2016). Effects of phytogenic feed additives on growth performance and on ammonia and greenhouse gases emissions in growing-finishing pigs. Anim. Feed Sci. Technol., 212: 143-148.

Botsoglou N.A, Florou-Paneri P., Christaki E., Fletouris D.J., Spais A.B. (2002). Effect of dietary oregano essential oil on performance of chickens and on iron-induced lipid oxidation of breast, thigh and abdominal fat tissues. Brit. Poultry Sci., 43: 223-230.

Brest off J.R., Artis D. (2013). Commensal bacteria at the interface of host metabolism and the immune system. Nat. Immunol., 14: 676-684.

Chw e n L.T., F o o H.L., T h a n h N.T., C h o e D.W. (2013). Growth performance, plasma fatty acids, villous height and crypt depth of preweaning piglets fed with medium chain triacylglycerol. AsianAustralas. J. Anim. Sci., 26: 700-704.

Costa L.B., Berenchtein B., Almeida V.V., Tse M.L.P., Braz D.B., Andrade C., M o urão G.B., Mi y ad a V.S. (2011). Phytobiotic additives and sodium butyrate as growth promoters of weanling pigs. Arch. Zootec., 60: 687-698.

F a n g C.L., S u n H., W u J., N i u H., F en g J. (2014). Effects of sodium butyrate on growth performance, haematological and immunological characteristics of weanling piglets. J. Anim. Physiol. Anim. Nutr., 98: 680-685. 
Fouhs e J.M., Zijlstra R.T., Willing B.P. (2016) The role of gut microbiota in the health and disease of pigs. Anim. Front., 6: 30-36.

GfE (2006). Empfehlungen zur Energie- und Nahrstoffversorgung von Schweinen. vol. 10. DLG-Verlag. Frankfurt am Main. Germany.

G h e i s a r M.M., K i m I.H. (2018). Phytobiotics in poultry and swine nutrition - a review. It. J. Anim. Sci., 17: 92-99.

Grajek K., Sip A., Foksowicz-Flaczyk J., Dobrowolska A., Wita A. (2016). Adhesive and hydrophobic properties of the selected LAB isolated from gastrointestinal tract of farming animals. Acta Bioch. Pol., 63: 311-314.

Gra s h or n M.A. (2010). Use of phytobiotics in broiler nutrition - an alternative to infeed antibiotics? J. Anim. Feed Sci., 19: 338-347.

H a n G.G., L e e J.Y., J in G.D., P a r k J., Ch o i Y.H., C h a e B.J. et al. (2016) Evaluating the association between body weight and the intestinal microbiota of weaned piglets via 16S rRNA sequencing. Appl. Microbiol. Biotechnol., 101: 5903-5911.

H a n c za kow s k a E., S z e w c zy k A., S w i t k i ew i c z M., O k o n K. (2013). Short- and medium-chain fatty acids as a feed supplement for weaning and nursery pigs. Pol. J. Vet. Sci. 16: 647-654.

Hill C., Guarner F., Reid G., Gibson G.R., Merenstein D.J., Pot B., Morelli L., C a nan i R.B., Flint H.J., S a $1 \mathrm{~m}$ in en S., Cald e r P.C., S a n d e r s M.E.. (2014). The international scientific association for probiotics and prebiotics consensus statement on the scope and appropriate use of the term probiotic. Nat. Rev. Gastroenterol. Hepatol. 11: 506-514.

H o n g S.M., H w a n g J.H., K i m I.H. (2012). Effect of medium-chain triglyceride (MCT) on growth performance, nutrient digestibility, blood characteristics in weanling pigs. Asian-Australas. J. Anim. Sci., 25: 1003-1008.

Houshmand M., Azhar K., Zulkifli I., B ejo M. H., Kamyab A. (2011). Effects of non antibiotic feed additives on performance, nutrient retention, gut $\mathrm{pH}$, and intestinal morphology of broilers fed different levels of energy. J. Appl. Poult. Res., 20: 121-128.

Huang C., Song P., F an P., Hou C., Thacker P., Ma X. (2015). Dietary sodium butyrate decreases postweaning diarrhea by modulating intestinal permeability and changing the bacterial communities in weaned piglets. J. Nutr., 145: 2774-2780.

L i Y., Z hang H., Yang L., Z hang L., Wang T. (2015). Effect of medium-chain triglycerides on growth performance, nutrient digestibility, plasma metabolites and antioxidant capacity in weanling pigs. Anim. Nutr., 1: 12-18

L i a o S.F., N y a c h o t i M. (2017). Using probiotics to improve swine gut health and nutrient utilization. Anim. Nutr., 3: 331-343.

Liu Y., Es pin os a C.D., Abelilla J.J., Cas as G.A., L. Lagos V., Le e S.A., Kwon W.B., M a th a i J.K., N a v a r ro D.M.D.L., J a w or s k i N.W., S t e i n H.H. (2018). Non-antibiotic feed additives in diets for pigs: A review. Anim. Nutr., https://doi.org/10.1016/j.aninu.2018.01.007

L ong S.F., X u Y.T., P a n L. Wang Q.Q., Wang C.L., Wu J.Y., Wu Y.Y., H a n Y.M., Yun C.H., $\mathrm{X}$ i ang sh u P. (2018). Mixed organic acids as antibiotic substitutes improve performance, serum immunity, intestinal morphology and microbiota for weaned piglets. Anim. Feed Sci. Technol., 235: 23-22.

Metge s C. (2010). Classical and post-genomic methods to study GIT function with emphasison the pig. Livest. Sci., 133: 10-19.

Metzler B., Ba uer E., Mos enthin R.. (2005). Microflora management in the gastrointestinal tract of piglets. Asian-Australas. J. Anim., 18: 1353-1362.

Meulen Van Der J., J an sman A. (1997). Nitrogen metabolism in gastrointestinal tissue of the pig. Proc. Nutr. Soc., 56: 535-545.

M uñ o z R., Tor M., Est a n y J. (2012). Relationship between blood lipid indicators and fat content and composition in Duroc pigs. Livest. Sci., 148: 95-102.

N a m kung H., L i M., G ong J., Yu H., C ottril1 M., D e L a n g e C.F.M. (2004). Impact of feeding blends of organic acids and herbal extracts on growth performance, gut microbiota and digestive function in newly weaned pigs. Can. J. Sci., 84: 697-704.

Nowak P., Kasprowicz-Potocka M., Zaworska A., Nowak W., Stefańska B., Sip A., Grajek W., Juzwa W., Taciak M., Barszcz M., Tuśnio A., Grajek K., Foksowicz-Flaczyk J., Frankiewicz A. (2017). The effect of eubiotic feed additives 
on the performance of growing pigs and the activity of intestinal microflora. Arch. Anim. Nutr., 71: 455-469.

Pereira C.M.C., Donzele J.L., de Oliveira Silva F.C., de Oliveira R.F.M., Kie fer C., Ferreira A.S., Hannas M.I., Brustolini P.C. (2012). Yeast extract with blood plasma in diets for piglets from 21 to 35 days of age. Rev. Brasil. Zoot., 41:1676-1682.

Piyadeat soontorn S., Taharnklaew R., Upathanpreecha T., Sornplang P. (2018). Encapsulating viability of multi-strain Lactobacilli as potential probiotic in pigs. Probiotics and Antimicrobial Proteins; doi: 10.1007/s12602-018-9418-7.

R a uw M., Portolés O., Corella D., S oler J., Re ix a ch J., T ib a u J., Prat J.M., Diaz I., G ó m e z - R a y a L. (2007). Behaviour influences cholesterol plasma levels in a pig model. Animal, 1: 865-871.

R o s e 11 V.L., Z i m m e r m a n D.R. (1985). Threonine requirement of pigs weighing 5 to $15 \mathrm{~kg}$ and the effect of excess methionine in diets marginal in threonine. J. Anim. Sci., 60: 480-486.

Santini C., Baffoni L., Gaggia F., Granata M., Gasbarri R., Di Gioia D., Biavati B. (2010). Characterization of probiotic strains: An application as feed additives in poultry against Campylobacter jejuni. Int. J. Food Microbiol., 141(Suppl 1): 98-108.

S u iry an rayn a M.V.A.N., R a m an a J.V. (2015). A review of the effects of dietary organic acids fed to swine. J. Anim. Sci. Biotechnol., 6: 45.

Un i Z., P l a t in R., S k l a n D. (1998). Cell proliferation in chicken intestinal epithelium occurs both in the crypt and along the villus. J. Comp. Physiol. B., 168: 241-247.

Vid a nara ch chi J.K., Mikkels en L.L,. S i m s I., I j i P.A., Cho ct M. (2005). Recent phytobiotics: alternatives to antibiotic growth promoters in monogastric animal feeds. Adv. Anim. Nutr. Austral., 15: 131-144.

W ind is ch W., S chedle K., P litzner C., Krois m a y A. (2008). Use of phytogenic products as feed additives for swine and poultry. J. Anim. Sci., 86: 140-148.

$\mathrm{W}$ in n i c k a A. (2011). The reference values of basic laboratory tests in veterinary medicine (in Polish). Wartości referencyjne podstawowych badań laboratoryjnych w weterynarii. Wydawnictwo SGGW.

Received: 23 VIII 2018

Accepted: 11 IV 2019 